\title{
Distribution of staphylococcal cassette chromosome mec (SCCmec) types I, II, III and IV in coagulase-negative staphylococci from patients attending a tertiary hospital in southern Brazil
}

\begin{abstract}
Correspondence
Alice Beatriz Mombach Pinheiro

Machado

abmachado@hcpa.ufrgs.br
\end{abstract}

Received 15 March 2007

Accepted 4 June 2007

\author{
Alice Beatriz Mombach Pinheiro Machado, Keli Cristine Reiter, \\ Rodrigo Minuto Paiva and Afonso Luis Barth \\ Unidade de Microbiologia e Biologia Molecular, Hospital de Clínicas de Porto Alegre, \\ Universidade Federal do Rio Grande do Sul, Porto Alegre 90.035-903, Brazil
}

\begin{abstract}
Coagulase-negative staphylococci (CoNS) are now recognized as the aetiological agents of an important range of infections in humans. Most developed countries have reported an increase in CoNS infections in hospitalized patients that are resistant to meticillin and other antibiotics. Staphylococcal cassette chromosome mec ( $\mathrm{SCC} m e c)$ typing is essential for understanding the molecular epidemiology of meticillin-resistant Staphylococcus strains. SCCmec elements are currently classified into types I to VI based on the characteristics of the mec and ccr gene complexes and are further classified into subtypes according to their 'junkyard DNA' region. We evaluated the distribution of SCCmec types in CoNS from patients attending the Hospital de Clínicas de Porto Alegre over the period August 2004-December 2005. Among the 129 bloodstream isolates, 36 (27.9\%) harboured SCCmec type I, 4 (3.0\%) harboured SCCmec type II, 67 (52\%) harboured SCCmec type III, 1 (0.8\%) harboured SCCmec type IV and 4 (3.0\%) harboured SCCmec types I and III. Seventeen isolates were not typable. Identification of CoNS at the species level indicated that Staphylococcus epidermidis was the most common species, with 87 isolates, followed by Staphylococcus haemolyticus (15), Staphylococcus hominis (13), Staphylococcus capitis (12) and Staphylococcus sciuri (1). SCCmec type III was the most prevalent among isolates of S. epidermidis (52\%). Among these strains, 30 (23\%) harboured a modified SCCmec type III which contained an additional dcs region in comparison with regular type III. SCCmec type III was also highly prevalent (75\%) among S. capitis isolates. The predominant SCCmec type found among S. haemolyticus isolates was type I. However, all four isolates harbouring $\mathrm{SCCmec}$ type II belonged to $S$. haemolyticus. Our results indicate that SCCmec type III was the most prevalent among the CoNS. Isolates with SCCmec type III were more resistant to non- $\beta$-lactam antimicrobials than isolates harbouring SCCmec types I, II and IV, although the increase in resistance was statistically significant only for clindamycin $(P=0.021)$, rifampicin $(P=0.010)$ and levofloxacin $(P=0.005)$.
\end{abstract}

\section{INTRODUCTION}

Coagulase-negative staphylococci (CoNS), particularly Staphylococcus epidermidis, are considered as the main pathogens of nosocomial bacteraemia associated with catheter and neonatal sepsis (Krediet et al., 2001, 2004). These infections are associated with high morbidity and mortality, mainly when CoNS are resistant to semisynthetic $\beta$-lactam antibiotics such as meticillin. In fact, meticillin-resistant Staphylococcus strains are a common

Abbreviations: CoNS, coagulase-negative staphylococci; MRSA, meticillin-resistant Staphylococcus aureus; SCC, staphylococcal cassette chromosome. cause of nosocomial infections worldwide (Wisplinghoff et al., 2004; Favre et al., 2005).

The resistance of CoNS to meticillin and other $\beta$-lactam antibiotics is mediated by a penicillin-binding protein which has reduced affinity for these antibiotics (PBP2a). This protein is encoded by the mecA gene (Chambers, 1988), inserted in a genomic island called staphylococcal cassette chromosome mec (SCCmec) (Ito et al., 2003). SCCmec is a mobile genetic element which is a vehicle for exchanging resistance genes between Staphylococcus strains and is widely distributed among CoNS species and in Staphylococcus aureus (Katayama et al., 2001; Ito et al., 1999; Hiramatsu et al., 2004; Ito et al., 2003). 
SCCmec was initially described as 'mec DNA', which was found only in meticillin-resistant $S$. aureus (MRSA) and absent in meticillin-sensitive $S$. aureus (MSSA) (Ito et al., 1999; Katayama et al., 2000). This genetic element is composed of different combinations between the mec complex, which encodes resistance to meticillin, and the $\mathrm{ccr}$ complex, which encodes recombinase enzymes responsible for the mobility of the genetic element. The mec complex is composed of IS431, mecA and intact or truncated sequences of mecI and mecRl regulatory genes. The $c c r$ complex can be composed of recombinase genes $c r r A$ and ccrB or $\operatorname{ccrC}$ (Ma et al., 2002; Chongtrakool et al., 2006; Ito et al., 2004, Oliveira et al., 2006; Kondo et al., 2007). Based on such diversity, six types of SCCmec have been described in $S$. aureus, and five types (I-V) have also been described in CoNS. Moreover, community meticillin-resistant $S$. epidermidis (C-MRSE) have been found with SCCmec type IV (Hisata et al., 2005; Wisplinghoff et al., 2003), and SCCmec type $\mathrm{V}$ has already been discovered in CoNS, particularly in Staphylococcus haemolyticus (Ito et al., 2004).

The structure and distribution of SCCmec types in $S$. aureus have been studied frequently (Chongtrakool et al., 2006; Hisata et al., 2005; Hiramatsu et al., 2004; Ito et al., 2001; Katayama et al., 2001), but data related to CoNS are only comparative and have been obtained in studies the purpose of which was to determine whether there was transmission between species (Hanssen et al., 2004; Hisata et al., 2005). In this study, we evaluated the distribution of SCCmec types I, II, III and IV in meticillin-resistant CoNS obtained from patients at a tertiary hospital in southern Brazil.

\section{METHODS}

Bacterial isolates. A total of 129 clinical isolates of meticillinresistant CoNS was obtained from blood cultures from 125 patients hospitalized at the Hospital de Clínicas de Porto Alegre between August 2004 and December 2005. The study included only one clinical isolate per patient, or more than one isolate when the second isolate was obtained after a 3 day interval. Blood cultures were processed using the BacT/Alert automated system (bioMérieux) and subcultured on trypticase soy agar containing $5 \%$ sheep blood (bioMérieux). Colony morphology, Gram stain reaction, the catalase test and the absence of coagulase were used to screen for CoNS.

Antimicrobial susceptibility testing. Antimicrobial susceptibility testing was performed by the disc diffusion method on MuellerHinton agar (bioMérieux) according to the recommendations of the CLSI (2006), with the following antibiotics: oxacillin $(1 \mu \mathrm{g})$, cefoxitin $(30 \mu \mathrm{g})$, vancomycin $(30 \mu \mathrm{g})$, gentamicin $(10 \mu \mathrm{g})$, clindamycin $(2 \mu \mathrm{g})$, chloramphenicol $(30 \mu \mathrm{g})$, doxycycline $(30 \mu \mathrm{g})$, erythromycin $(15 \mu \mathrm{g})$, levofloxacin $(5 \mu \mathrm{g})$, rifampicin $(5 \mu \mathrm{g})$ and trimethoprim/ sulfamethoxazole (co-trimoxazole) $(25 \mu \mathrm{g})$. S. aureus ATCC 25923 was used for quality control.

DNA extraction and quantification. The isolates were cultured on Mueller-Hinton agar incubated at $35{ }^{\circ} \mathrm{C}$ for $18-24 \mathrm{~h}$. A bacterial suspension equivalent to $1.0 \mathrm{McFarland}$ standard was prepared in $500 \mu \mathrm{TE}(10 \mathrm{mM}$ Tris/ $\mathrm{HCl}, 1 \mathrm{mM}$ EDTA, $\mathrm{pH}$ 8.0). The suspension was homogenized by vortexing and heated at $100{ }^{\circ} \mathrm{C}$ for $10 \mathrm{~min}$
(York et al., 1996), frozen at $-20{ }^{\circ} \mathrm{C}$ for $2 \mathrm{~h}$ and then centrifuged at $9000 \mathrm{~g}$ for $3 \mathrm{~min}$. The DNA from non-typable isolates and 20 random isolates was quantified using the GeneQuant RNA/DNA calculator (Amersham Pharmacia). Non-typable isolates were submitted to thermal lysis and then extracted using a QIAamp kit for tissues (Qiagen) according to the manufacturer's instructions.

Species identification. Molecular identification of S. epidermidis was performed by PCR of the $t u f$ gene with primers from a speciesspecific probe for identification (Martineau et al., 1996). Isolates that were not identified as S. epidermidis were tested in the API ID 32 STAPH semi-automated system (bioMérieux).

Determination of the $\boldsymbol{m e c} \boldsymbol{A}$ gene. PCR for the mecA gene was performed according to the protocol described by Vannuffel et al. (1995). S. epidermidis ATCC 12228 and S. aureus ATCC 33591 were used as negative and positive controls, respectively.

Determination of SCCmec type. The SCCmec type was determined in a multiplex PCR which included four pairs of primers for loci A, B, D and E (Oliveira \& de Lencastre, 2002). Locus A is exclusive to SCCmec type I and amplifies a region of the pls gene, locus B is exclusive to SCCmec type II and amplifies an internal region of the $k p d$ operon, locus D is common to SCCmec types I, II and IV and amplifies a region of the $d c s$ gene and locus $\mathrm{E}$ is exclusive to SCCmec type III and amplifies a region between integrated plasmid pI258 and transposon Tn554 (Fig. 1) In addition, a single PCR for each locus was standardized in order to check results for 30 isolates which amplified locus $\mathrm{E}$ and $\mathrm{D}$ and the results of the non-interpretable types obtained by multiplex PCR.

Multiplex PCR was performed in $50 \mu \mathrm{l}$ reactions with $1 \times$ enzyme buffer (JMR Holdings), 1.25 U Taq polymerase DNA (SuperTherm; JMR Holdings), $200 \mu \mathrm{M}$ dNTPs (ABgene), 10 pmol each of primers CIF2 F2 and CIF2 R2, 6 pmol each of primers KDP F1 and KDP R1, 5 pmol each of primers DCS F2 and DCS R1 and 5 pmol each of primers RIF4 F3 and RIF4 R9 (Invitrogen) and $10 \mu$ l extracted DNA. The amplification process was performed using an MJ Research PTC 100 Thermocycler. Each single PCR was performed in a $25 \mu$ reaction following the same protocol as for the multiplex PCR.

Cycle sequencing reactions were performed at $92{ }^{\circ} \mathrm{C}$ for $3 \mathrm{~min}$ followed by 30 cycles of $92{ }^{\circ} \mathrm{C}$ for $1 \mathrm{~min}, 56{ }^{\circ} \mathrm{C}$ for $1 \mathrm{~min}$ and $72{ }^{\circ} \mathrm{C}$ for $1.5 \mathrm{~min}$ for both protocols. PCR products were detected on a $2 \%$ agarose gel and stained with ethidium bromide.

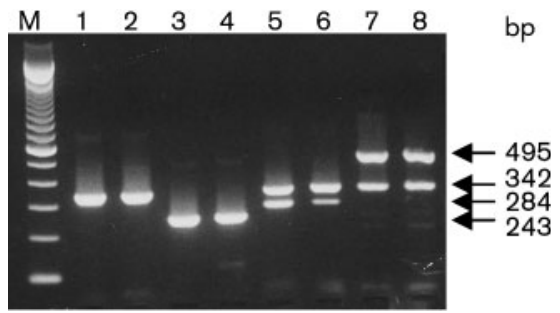

Fig. 1. Multiplex PCR for SCCmec type from CoNS. Lanes: $M$, molecular size standard (100 bp ladder); 1 and 2, isolate 173 (S. epidermidis) harbouring SCCmec IV (342 bp); 3 and 4, isolate 110 (S. capitis) harbouring SCCmec III (243 bp); 5 and 6, isolate 109 (S. haemolyticus) harbouring SCCmec II (342 and 284 bp); 7 and 8, isolate 204 (S. epidermidis) harbouring SCCmec I (342 and $495 \mathrm{bp}$ ). 
Sequencing and computer analysis of sequences. Using the DNA fragments amplified by single PCR, the nucleotide sequences of loci $\mathrm{A}, \mathrm{B}, \mathrm{D}$ and $\mathrm{E}$ and the $m e c \mathrm{~A}$ gene were determined. A sequence similarity search was performed with BLAST and Chromas programs and the DDBJ/EMBL/GeneBank databases.

Statistical analysis. The chi-squared test with a 0.05 significance level was used for statistical analysis. A descriptive statistical analysis was performed to evaluate the relationship between antimicrobial susceptibility and SCCmec type.

\section{RESULTS AND DISCUSSION}

A wide distribution of the mecA gene in CoNS species has been demonstrated in previous studies (Pierre et al., 1990) and was confirmed in our study of CoNS clinical isolates belonging to five species. This study also described the distribution of the SCCmec types I, II, III and IV among a population of CoNS from blood cultures obtained from patients at a tertiary hospital.

The presence of the mecA gene was tested in all 129 isolates of meticillin-resistant CoNS by PCR using specific primers, and all isolates gave a positive result. Sequencing of the amplified fragment of the $m e c A$ gene from one clinical sample gave $100 \%$ similarity with the mecA gene sequence for S. aureus strain N315 (GenBank accession no. D86934), demonstrating that this gene is well-conserved in Staphylococcus species (Ito et al., 2001). This isolate was used as a positive control in all PCR tests.

There was agreement of 100 and $97 \%$ in disc diffusion testing with cefoxitin and oxacillin, respectively, with the presence of the mecA gene, detected by PCR in all 129 isolates. The disc diffusion test with a cefoxitin substrate is preferred over the test with oxacillin to estimate resistance to oxacillin mediated by the mecA gene for both $S$. aureus and CoNS (Swenson et al., 2005). This was also observed in our study.

Identification of CoNS species was performed in two stages. First, all 129 isolates were tested using a speciesspecific primer for the tuf gene, and $87(67.4 \%)$ of the isolates were identified as $S$. epidermidis. The remaining 42 isolates were identified using a semi-automated system, resulting in $15(11.6 \%) S$. haemolyticus, $13(10 \%) S$. hominis, 12 (9.3\%) S. capitis and 1 (0.8\%) S. sciuri isolates and one isolate that could not be identified. These represent the meticillin-resistant CoNS species usually found in the clinical microbiology laboratory (Caierão et al., 2006; York et al., 1996; Silva et al., 2002).

The multiplex PCR for the four SCCmec types (I, II, III and IV) identified $36(28 \%)$ isolates with SCCmec type I, 4 $(3.0 \%)$ with SCCmec type II, 67 (52\%) with SCCmec type III, of which 30 were positive for both SCCmec types III and IV, $1(0.8 \%)$ with SCCmec type IV and $4(3.0 \%)$ isolates positive for two SCCmec types, I and III (Fig. 1). Seventeen isolates $(13 \%)$ were not typable by the method employed (Table 1). These results are comparable to the distribution of SCCmec types among staphylococci in an earlier study (Chung et al., 2004), but differed from another study where SCCmec type IV was the most prevalent in hospital isolates of $S$. epidermidis (Wisplinghoff et al., 2003).

Non-typable CoNS were tested by PCR using single primers for the four loci, but we were not able to establish the SCCmec type of these isolates. Most (59\%) of the nontypable isolates were identified as S. hominis. The relatively large number of non-typable isolates may be due to the fact that a few variants of SCCmec type II do not have the $k p d$ operon in the 'junkyard region' and, therefore, they cannot be identified as SCCmec type II using this multiplex PCR (Shore et al., 2005). Moreover, Shore et al. (2005) described a variant of SCCmec type IV which did not present locus D of the dcs region and named it SCCmec type IV-dcs. It is possible that some of our non-typable strains could be SCCmec type IV-dcs. The variability in the identification of SCCmec might also be explained by the presence of novel structures or rearrangements and recombinations of the mec element (Chung et al., 2004; Zhang et al., 2005).

The distribution of SCCmec types among the S. epidermidis isolates indicated that $25(19 \%)$ isolates harboured SCCmec type I and $24(18.6 \%)$ harboured SCCmec type III. Interestingly, $30(23 \%)$ isolates harboured both SCCmec type III and locus D (type IV). All isolates with this profile were identified as $S$. epidermidis, and this may indicate the existence of a clonal relationship among these

Table 1. Distribution of SCCmec elements among meticillin-resistant CoNS

Values are numbers of isolates (percentages of total number of isolates).

\begin{tabular}{|lccccccc|}
\hline SCCmec type & Total & S. epidermidis & S. hominis & S. haemolyticus & S. capitis & S. sciuri & Not identified \\
\hline I & 36 & $25(19.4)$ & $0(0)$ & $10(7.8)$ & $1(0.8)$ & $0(0)$ & $0(0)$ \\
II & 4 & $0(0)$ & $0(0)$ & $4(3.1)$ & $0(0)$ & $0(0)$ & $0(0)$ \\
III & 37 & $24(18.6)$ & $3(2.3)$ & $0(0)$ & $9(7)$ & $1(0.8)$ & $0(0)$ \\
IV & 1 & $1(0.8)$ & $0(0)$ & $0(0)$ & $0(0)$ & $0(0)$ & $0(0)$ \\
I and III & 4 & $4(3.1)$ & $0(0)$ & $0(0)$ & $0(0)$ & $0(0)$ & $0(0)$ \\
III and IV & 30 & $30(23.2)$ & $0(0)$ & $0(0)$ & $0(0)$ & $0(0)$ & $0(0)$ \\
Non-typable & 17 & $3(2.3)$ & $10(7.8)$ & $1(0.8)$ & $2(1.5)$ & $0.8)$ \\
\hline
\end{tabular}


isolates. These results warrant further studies using another molecular typing technique. It was possible to identify only one $(0.8 \%)$ isolate with SCCmec type IV. On the other hand, four $(3.1 \%)$ isolates resulted in amplification of the loci for SCCmec types I and III and were considered as non-interpretable.

The 30 isolates of S. epidermidis that harboured SCCmec type III (locus E) and the dcs region (locus D) were tested again by single PCRs for locus D and locus E. These PCRs confirmed the amplification of both loci in all 30 isolates. The presence of locus $\mathrm{D}$ ( $d c s$ region) is not exclusive to SCCmec types I, II and IV; Chongtrakool et al. (2006) identified 39 isolates with locus D and SCCmec type III. This profile has also been found in other studies. In order to investigate the nature of these cassettes, genes of the $\mathrm{crr}$ complex were characterized, and it was shown that a few isolates with typical SCCmec type III also gave an amplification product for locus $\mathrm{D}$ and contained the ccrAB3 type (Aires de Sousa \& de Lencastre, 2003; Budimir et al., 2006; Qi et al., 2005).

Among the 15 isolates of S. haemolyticus, 10 (7.8\%) harboured SCCmec type I, 4 (3.1\%) harboured SCCmec type II and $1(0.8 \%)$ isolate harboured an SCCmec type that could not be identified. Among the 13 isolates identified as $S$. hominis, SCCmec type identification could not be performed in $10(7.8 \%)$ isolates, and only $3(2.3 \%)$ were identified, as SCCmec type III. Among the 12 isolates classified as S. capitis, $1(0.8 \%)$ harboured SCCmec type I and $9(7 \%)$ harboured SCCmec type III, but it was not possible to identify the SCCmec type in $2(1.5 \%)$ isolates.

Molecular typing techniques such as multilocus sequence typing (MLST), SCCmec typing and others have shown that most nosocomial MRSA infections are caused by a few pandemic clones. Among the five representative MRSA pandemic types characterized by MLST is clonal complex 8 (CC8), which includes a Brazilian clone (ST 239) with SCCmec IIIA (Shore et al., 2005; Robinson \& Enright, 2003). The hypothesis of SCCmec transfer between species of staphylococci may provide a mechanism to explain the detection of CoNS isolates of this study, often identified as SCCmec III, which are related to the presence of this MRSA pandemic clone in our institution (data not shown).

The hypothesis of SCCmec transfer between S. epidermidis and $S$. aureus is based on several pieces of evidence. Hanssen et al. (2004) found genetically unique MRSA containing variants of $c c r A B$ genes that are identical to those found in meticillin-resistant CoNS. It seems that $S$. aureus and CoNS contain the same pool of genes, with resistance and recombinase genes; however, it is still necessary to define the resistance-transfer mechanisms and routes between staphylococci.

Sequencing of amplified loci to identify SCCmec types I, II, III and IV gave $100 \%$ similarity. The differences were only in point mutations in one of the two strands. The amplicons were compared to sequences from GenBank with accession numbers AB033763 for SCCmec type I, D86934 for SCCmec type II, AB037671 for SCCmec type III and AB033763 for SCCmec type IV. These isolates were used as positive controls in the PCRs. The sequences of two selected isolates that amplified SCCmec type III and type IV (locus D) showed $100 \%$ similarity to a type IVb sequence deposited in GenBank under accession number AB063173, but only $96 \%$ similarity to SCCmec type III (AB037671).

A descriptive analysis of resistance was performed for the susceptibility profile of CoNS to non- $\beta$-lactam antimicrobials among SCCmec types (Table 2). According to the literature, isolates containing SCCmec type III contain a large number of resistance genes (Ito et al., 1999, 2001). In this study, we also found isolates with SCCmec III to be more resistant to non- $\beta$-lactam antibiotics, but this difference was not statistically significant for most antibiotics (erythromycin, $P=0.171$; doxycycline, $P=0.982$; trimethoprim/sulfamethoxazole, $P=0.115$; gentamicin, $P=0.860$; and chloramphenicol, $P=0.358)$, the exceptions being rifampicin $(P=0.010)$, levofloxacin $(P=0.005)$ and clindamycin $(P=0.012)$.

CoNS are reservoirs of resistance genes and are probably able to transmit these genes to $S$. aureus. The similarity of

Table 2. Distribution of non- $\beta$-lactam antibiotic resistance among 129 isolates of meticillin-resistant CoNS by SCCmec type

Values are numbers of isolates (percentages of isolates of that type).

\begin{tabular}{|lllclr|}
\hline Antibiotic & I $(\boldsymbol{n}=\mathbf{3 6})$ & II $(\boldsymbol{n}=\mathbf{4})$ & III $(\boldsymbol{n}=\mathbf{6 7})$ & IV $(\boldsymbol{n}=\mathbf{1})$ & Non-typable $(\boldsymbol{n}=\mathbf{1 7})$ \\
\hline Clindamycin & $24(66.6)$ & $1(25)$ & $48(73.8)$ & $1(100)$ & $6(37.5)$ \\
Chloramphenicol & $18(50)$ & $0(0)$ & $25(39.1)$ & $0(0)$ & $5(31.3)$ \\
Doxycycline & $12(33.3)$ & $0(0)$ & $8(12.5)$ & $0(0)$ & $5(31.3)$ \\
Erythromycin & $28(71.4)$ & $1(25)$ & $49(75.4)$ & $1(100)$ & $10(62.5)$ \\
Gentamicin & $33(91.7)$ & $2(50)$ & $58(89.2)$ & $1(100)$ & $13(81.3)$ \\
Levofloxacin & $14(38.9)$ & $1(25)$ & $43(70.5)$ & $1(100)$ & $5(37.5)$ \\
Rifampicin & $10(27.8)$ & $0(0)$ & $21(32.3)$ & $1(100)$ & $3(18.8)$ \\
Co-trimoxazole & $24(66.6)$ & $1(25)$ & $51(78.5)$ & $1(100)$ & $13(81.3)$ \\
Vancomycin & $0(0)$ & $0(0)$ & $0(0)$ & $0(0)$ & $0(0)$ \\
& & & & & \\
\hline
\end{tabular}


SCCmec regions among $S$. aureus and CoNS suggests horizontal transmission between species of Staphylococcus. In addition, the extensive rearrangement observed in $c c r$ and mec complexes indicates the frequent exchange of genetic material (Hanssen \& Ericson Sollid, 2006).

It is noteworthy that SCCmec type IV was first identified in S. epidermidis in 1970 and only described around 10 years later in S. aureus (Wisplinghoff et al., 2003). One could consider, therefore, that the SCCmec type III found in the widely distributed MRSA in Brazil (Brazilian clone) may have originated from CoNS (Da Silva Coimbra et al., 2000).

The most relevant point is that SCCmec type III encodes the largest number of resistance genes, and this information is epidemiologically important for institutional infection control. Traditionally, CoNS have been recognized as bacteria of minor clinical importance; however, they may now be considered one of the factors that determines the generation of new MRSA strains.

\section{REFERENCES}

Aires de Sousa, M. \& de Lencastre, H. (2003). Evolution of sporadic isolates of methicillin-resistant Staphylococcus aureus (MRSA) in hospitals and their similarities to isolates of community-acquired MRSA. J Clin Microbiol 41, 3806-3815.

Budimir, A., Deurenberg, R. H., Plecko, V., Vink, C., Kalenic, S. \& Stobberingh, E. E. (2006). Molecular characterization of methicillinresistant Staphylococcus aureus bloodstream isolates from Croatia. J Antimicrob Chemother 57, 331-334.

Caierão, J., Superti, S., Dias, C. A. \& d'Azevedo, P. A. (2006). Automated systems in the identification and determination of methicillin resistance among coagulase negative staphylococci. Mem Inst Oswaldo Cruz 101, 277-280.

Chambers, H. F. (1988). Methicillin-resistant staphylococci. Clin Microbiol Rev 1, 173-186.

Chongtrakool, P., Ito, T., Ma, X. X., Kondo, Y., Trakulsomboon, S., Tiensasitorn, C., Jamklang, M., Chavalit, T., Song, J. H. \& Hiramatsu, K. (2006). Staphylococcal cassette chromosome mec (SCCmec) typing of methicillin-resistant Staphylococcus aureus strains isolated in 11 Asian countries: a proposal for a new nomenclature for SCCmec elements. Antimicrob Agents Chemother 50, 1001-1012.

Chung, M., Dickinson, G., De Lencastre, H. \& Tomasz, A. (2004). International clones of methicillin-resistant Staphylococcus aureus in two hospitals in Miami, Florida. J Clin Microbiol 42, 542-547.

CLSI (2006). Performance standards for antimicrobial susceptibility testing. Informational Supplement M100-S16. Wayne, PA: Clinical and Laboratory Standards Institute.

Da Silva Coimbra, M. V., Teixeira, L. A., Ramos, R. L. B., Predari, S. C., Castello, L., Famiglietti, A., Vay, C., Klan, L. \& Figueiredo, A. M. S. (2000). Spread of the Brazilian epidemic clone of a multiresistant MRSA in two cities in Argentina. J Med Microbiol 49, 187-192.

Favre, B., Hugonnet, S., Correa, L., Sax, H., Rohner, P. \& Pittet, D. (2005). Nosocomial bacteremia: clinical significance of a single blood culture positive for coagulase-negative staphylococci. Infect Control Hosp Epidemiol 26, 697-702.

Hanssen, A. M. \& Ericson Sollid, J. U. (2006). SCCmec in staphylococci: genes on the move. FEMS Immunol Med Microbiol 46, 8-20.
Hanssen, A. M., Kjeldsen, G. \& Sollid, J. U. (2004). Local variants of staphylococcal cassette chromosome mec in sporadic methicillinresistant Staphylococcus aureus and methicillin-resistant coagulasenegative staphylococci: evidence of horizontal gene transfer? Antimicrob Agents Chemother 48, 285-296.

Hiramatsu, K., Watanabe, S., Takeuchi, F., Ito, T. \& Baba, T. (2004). Genetic characterization of methicillin-resistant Staphylococcus aureus. Vaccine 22 (Suppl. 1), S5-S8.

Hisata, K., Kuwahara-Arai, K., Yamanoto, M., Ito, T., Nakatomi, Y., Cui, L., Baba, T., Terasawa, M., Sotozono, C. \& other authors (2005). Dissemination of methicillin-resistant staphylococci among healthy Japanese children. J Clin Microbiol 43, 3364-3372.

Ito, T., Katayama, Y. \& Hiramatsu, K. (1999). Cloning and nucleotide sequence determination of the entire mec DNA of pre-methicillinresistant Staphylococcus aureus N315. Antimicrob Agents Chemother 43, 1449-1458.

Ito, T., Katayama, Y., Asada, K., Mori, N., Tsutsumimoto, K., Tiensasitorn, C. \& Hiramatsu, K. (2001). Structural comparison of three types of staphylococcal cassette chromosome mec integrated in the chromosome in methicillin-resistant Staphylococcus aureus. Antimicrob Agents Chemother 45, 1323-1336.

Ito, T., Okuma, K., Ma, X. X., Yuzawa, H. \& Hiramatsu, K. (2003). Insights on antibiotic resistance of Staphylococcus aureus from its whole genome: genomic island SCC. Drug Resist Updat 6, 41-52.

Ito, T., Ma, X. X., Takeuchi, F., Okuma, K., Yuzawa, H. \& Hiramatsu, K. (2004). Novel type V staphylococcal cassette chromosome mec driven by a novel cassette chromosome recombinase, ccrC. Antimicrob Agents Chemother 48, 2637-2651.

Katayama, Y., Ito, T. \& Hiramatsu, K. (2000). A new class of genetic element, staphylococcus cassette chromosome mec, encodes methicillin resistance in Staphylococcus aureus. Antimicrob Agents Chemother 44, 1549-1555.

Katayama, Y., Ito, T. \& Hiramatsu, K. (2001). Genetic organization of the chromosome region surrounding $m e c A$ in clinical staphylococcal strains: role of IS431-mediated mecI deletion in expression of resistance in mecA-carrying, low-level methicillin-resistant Staphylococcus haemolyticus. Antimicrob Agents Chemother 45, 1955-1963.

Kondo, Y., Ito, T., Ma, X. X., Watanabe, S., Kreiswirth, B. N., Etienne, J. \& Hiramatsu, K. (2007). Combination of multiplex PCRs for staphylococcal cassette chromosome mec type assignment: rapid identification system for mec, $c c r$, and major differences in junkyard regions. Antimicrob Agents Chemother 51, 264-274.

Krediet, T. G., Jones, M. E., Janssen, K., Gerards, L. J. \& Fleer, A. (2001). Prevalence of molecular types and mecA gene carriage of coagulase-negative staphylococci in a neonatal intensive care unit: relation to nosocomial septicemia. J Clin Microbiol 39, 3376-3378.

Krediet, T. G., Mascini, E. M., van Rooij, E., Vlooswijk, J., Paauw, A., Gerards, L. J. \& Fleer, A. (2004). Molecular epidemiology of coagulasenegative staphylococci causing sepsis in a neonatal intensive care unit over an 11-year period. J Clin Microbiol 42, 992-995.

Ma, X. X., Ito, T., Tiensasitorn, C., Jamklang, M., Chongtrakool, P., Boyle-Vavra, S., Daum, R. S. \& Hiramatsu, K. (2002). Novel type of staphylococcal cassette chromosome mec identified in communityacquired methicillin-resistant Staphylococcus aureus strains. Antimicrob Agents Chemother 46, 1147-1152.

Martineau, F., Picard, F. J., Roy, P. H., Ouellette, M. \& Bergeron, M. G. (1996). Species-specific and ubiquitous-DNA-based assays for rapid identification of Staphylococcus epidermidis. J Clin Microbiol 34, 2888-2893.

Oliveira, D. C. \& de Lencastre, H. (2002). Multiplex PCR strategy for rapid identification of structural types and variants of the mec 
element in methicillin-resistant Staphylococcus aureus. Antimicrob Agents Chemother 46, 2155-2161.

Oliveira, D. C., Milheiriço, C. \& de Lencastre, H. (2006). Redefining a structural variant of staphylococcal cassette chromosome mec, SCCmec type VI. Antimicrob Agents Chemother 50, 3457-3459.

Pierre, J., Williamson, R., Bornet, M. \& Gutmann, L. (1990). Presence of an additional penicillin-binding protein in methicillin-resistant Staphylococcus epidermidis, Staphylococcus haemolyticus, Staphylococcus hominis, and Staphylococcus simulans with a low affinity for methicillin, cephalothin, and cefamandole. Antimicrob Agents Chemother 34, 1691-1694.

Qi, W., Ender, M., O'Brien, F., Imhof, A., Ruef, C., McCallum, N. \& Berger-Bachi, B. (2005). Molecular epidemiology of methicillinresistant Staphylococcus aureus in Zurich, Switzerland (2003) prevalence of type IV SCCmec and a new SCCmec element associated with isolates from intravenous drug users. J Clin Microbiol 43, 5164-5170.

Robinson, D. A. \& Enright, M. C. (2003). Evolutionary models of the emergence of methicillin-resistant Staphylococcus aureus. Antimicrob Agents Chemother 47, 3926-3934.

Shore, A., Rossney, A. S., Keane, C. T., Enright, M. C. \& Coleman, D. C. (2005). Seven novel variants of the staphylococcal chromosomal cassette mec in methicillin-resistant Staphylococcus aureus isolates from Ireland. Antimicrob Agents Chemother 49, 2070-2083.

Silva, G. D., Kantzanou, M., Justice, A., Massey, R. C., Wilkinson, A. R., Day, N. P. \& Peacock, S. J. (2002). The ica operon and biofilm production in coagulase-negative staphylococci associated with carriage and disease in a neonatal intensive care unit. $J$ Clin Microbiol 40, 382-388.

Swenson, J. M. \& Tenover, F. C.Cefoxitin Disk Study Group (2005). Results of disk diffusion testing with cefoxitin correlate with presence of mecA in Staphylococcus spp. J Clin Microbiol 43, 3818-3823.

Vannuffel, P., Gigi, J., Ezzedine, H., Vandercam, B., Delmee, M., Wauters, G. \& Gala, J. L. (1995). Specific detection of methicillinresistant Staphylococcus species by multiplex PCR. J Clin Microbiol 33, 2864-2867.

Wisplinghoff, H., Rosato, A. E., Enright, M. C., Noto, M., Craig, W. \& Archer, G. L. (2003). Related clones containing SCCmec type IV predominate among clinically significant Staphylococcus epidermidis isolates. Antimicrob Agents Chemother 47, 3574-3579.

Wisplinghoff, H., Bischoff, T., Tallent, S. M., Seifert, H., Wenzel, R. P. \& Edmond, M. B. (2004). Nosocomial bloodstream infections in US hospitals: analysis of 24,179 cases from a prospective nationwide surveillance study. Clin Infect Dis 39, 309-317.

York, M. K., Gibbs, L., Chehab, F. \& Brooks, G. F. (1996). Comparison of PCR detection of mecA with standard susceptibility testing methods to determine methicillin resistance in coagulase-negative staphylococci. J Clin Microbiol 34, 249-253.

Zhang, K., McClure, J. A., Elsayed, S., Louie, T. \& Conly, J. M. (2005). Novel multiplex PCR assay for characterization and concomitant subtyping of staphylococcal cassette chromosome mec types I to $\mathrm{V}$ in methicillin-resistant Staphylococcus aureus. J Clin Microbiol 43, 5026-5033. 